OPEN ACCESS

Edited by:

Wengui Li

University of Technology Sydney,

Australia

Reviewed by: Luming Shen,

The University of Sydney, Australia

Jingwei Ying,

Guangxi University, China

Zhiyong Liu,

Southeast University, China

*Correspondence:

Xingguo Wang

paulw@hpu.edu.cn

Xianggang Zhang

xgzhang@hpu.edu.cn

Specialty section: This article was submitted to

Structural Materials,

a section of the journal

Frontiers in Materials

Received: 01 February 2021 Accepted: 29 March 2021

Published: 28 April 2021

Citation:

Wang $X$, Jiang $M$, Zhang $X$, Cheng Z, Gong J and Cheng F (2021) Effects of Different Strain Rates on the Impact Properties of Recycled Aggregate Concrete Modified With

Nanosilica Solution and Polyvinyl Alcohol Fiber. Front. Mater. 8:662374.

doi: 10.3389/fmats.2021.662374

\section{Effects of Different Strain Rates on the Impact Properties of Recycled Aggregate Concrete Modified With Nanosilica Solution and Polyvinyl Alcohol Fiber}

\author{
Xingguo Wang ${ }^{1,2 *}$, Maolin Jiang ${ }^{1}, X_{i a n g g a n g}$ Zhang $^{1,2,3 *}$, Zhaoxia Cheng ${ }^{1}$, Jian Gong ${ }^{1}$ \\ and Fei Cheng ${ }^{1}$
}

\footnotetext{
${ }^{1}$ School of Civil Engineering, Henan Polytechnic University, Jiaozuo, China, ${ }^{2}$ International Joint Laboratory of Henan Province for Underground Space and Disaster Prevention, Jiaozuo, China, ${ }^{3}$ Henan Key Laboratory of Special Protective Materials, Luoyang, China
}

The recycled aggregate (RA) was modified by $2 \%$ nanosilica solution, and the split Hopkinson pressure bar (SHPB) test device was used to study the dynamic impact properties of the modified recycled aggregate concrete (RAC) mixed with polyvinyl alcohol (PVA) fibers. The RA replacement percentage, the amount of PVA fiber, and the strain rate were variables. The failure pattern, the stress-strain curve of the nanosilica solution, and PVA fiber-modified RAC were shown under different strain rate conditions. Dynamic peak stress, peak strain, and dynamic increase factor (DIF) of the specimens are discussed. The results showed that the stress and dynamic peak strain value of the specimen increased with the increase of the strain rate; moreover, with the increase of the RA replacement percentage and the PVA fiber content, the dynamic peak stress of the specimen decreases, while the dynamic peak strain and the DIF value increase. The incorporation of nanosilica-modified RA is beneficial to the improvement of the impact performance of RAC, and the incorporation of an appropriate amount of the PVA fiber effectively improves the deformability of RAC.

Keywords: recycled aggregate concrete, nanosilica, split Hopkinson pressure bar, polyvinyl alcohol fiber, impact performance

\section{INTRODUCTION}

Recycled aggregate concrete (RAC) is an effective way for the utilization of solid waste in construction, but its mechanical properties still have certain defects compared with the natural aggregate concrete (NAC), and the randomness and variability of recycled aggregates (RAs) are more obvious. Compared with natural aggregate (NA), an old mortar with cracks and pores is attached to the surface of RAs, which makes RAs to have a low apparent density, high porosity, and high water absorption rate, resulting in decreased elastic modulus of RAC and increased shrinkage 
deformation. And, the old mortar and the interface transition zone (ITZ) were the main weak links of RAC (Xiao et al., 2012). The split tensile strength of RAC was reduced by 10-25\% compared with NAC (Tabsh and Abdelfatah, 2009). When the RA replacement percentage increased to $100 \%$, the compressive strength of RAC decreased by $19 \%$ and the split tensile strength decreased by $19 \%$ (Thomas et al., 2018). As the RA replacement percentage increased, the flexural strength of RAC decreased (Topçu and Şengel, 2004). However, there were exceptions that the incorporation of RAs increases the strength of RAC (Mohanraj et al., 2011). Different sources of RAs increased the coefficient of variation of RAC; RAs with better grades and quality could improve the strength of RAC (Manzi et al., 2013). The change in the compressive strength of RAC was mainly affected by the water-cement ratio of the original concrete (Hansen, 1986) and may also be affected by the original cumulative damage.

The mechanical properties of RAC were related to the characteristics of RA. Nanomaterial modification (Wang et al., 2020), mineral additives (Tangchirapat et al., 2010), and fiber doping (Jalal et al., 2017) could improve the microproperties of the ITZ and can enhance the destructive performance of RAC. The hydration residues of small particles, such as cement and mineral additives, had a large porosity, and there are relatively dense calcium silicate hydrate (C-S-H) gels around them, the size of which is in nanometers (Richardson, 1999), making the application of nanomaterials possible. Nanosilica was more conducive to improve the performance of the ITZ and the density of the mortar than the silica fume (Bernal et al., 2018). Adding 3\% nanosilica reduced the workability and the fluidity of RAC but could effectively improve the impermeability and viscosity of RAC (Hosseini et al., 2011). Adding nanosilica improved the property of ITZ between the new and old mortar of RAC and strengthened the surface of the old mortar, which improved the crack resistance of the specimens. However, it was not obvious to improve the property of ITZ between the RA and the old mortar (Zhang et al., 2015). Adding $1 \%$ nano- $\mathrm{SiO}_{2}$ and $3 \%$ nano- $\mathrm{CaCO}_{3}$ concentration could effectively improve the compressive strength and flexural strength of RAC (Li et al., 2015). Moreover, 2\% nanosilica and $1 \%$ steel fiber could also significantly enhance the compressive strength and mechanical properties of the geopolymer concrete (Their and Özakça, 2018).

Soaking RA in the polyvinyl alcohol (PVA) solution could effectively reduce the water absorption of RA (Kou and Poon, 2010). The presence of the PVA film delayed the hydration time of the cement and the PVA slurry, reducing the compressive strength of RAC but significantly improving the flexural performance of RAC (Yaowarat et al., 2018). The related PVA fiber has high strength and modulus, good alkali resistance and weather resistance, and good bonding performance with cement.
TABLE 1 | Physical properties of natural aggregate (NA), recycled aggregate (RA), and nanosilica-recycled aggregate (SRA).

\begin{tabular}{|c|c|c|c|c|}
\hline $\begin{array}{l}\text { Aggregate } \\
\text { type }\end{array}$ & $\begin{array}{c}\text { Particle } \\
\text { size }(\mathrm{mm})\end{array}$ & $\begin{array}{c}\text { Apparent } \\
\text { density }\left(\mathrm{kg} / \mathrm{m}^{3}\right)\end{array}$ & $\begin{array}{l}\text { Crushing } \\
\text { index (\%) }\end{array}$ & $\begin{array}{c}\text { Water } \\
\text { absorption (\%) }\end{array}$ \\
\hline $\mathrm{NA}$ & $5 \sim 20$ & 2,712 & 8.30 & 0.38 \\
\hline RA & $5 \sim 20$ & 2,564 & 19.70 & 4.80 \\
\hline SRA & $5 \sim 20$ & 2,605 & 15.85 & 3.77 \\
\hline
\end{tabular}

Incorporating the PVA fiber reduced the drying shrinkage of the concrete and improved its crack resistance (Wang et al., 2017). Most research focused on the static mechanical properties of RAC and its modified specimens.

However, it is necessary to study the dynamic mechanical properties of RAC. The strain rate had an important effect on the impact performance of RAC (Liu et al., 2018). With the increase of strain rates, the stress and strain value of specimens increased. As the RA replacement percentage increased, the peak strain and the dynamic increase factor (DIF) value of the specimens increased, while the peak stress decreased (Xiao et al., 2015). The modification of nanoparticles (nano- $\mathrm{SiO}_{2}$, nano- $\mathrm{CaCO}_{3}$ ) could effectively improve the impact strength of RAC and showed a lower strain rate sensitivity, while the modification effect of the nanosilica is better (Li et al., 2016). Adding the fiber could effectively increase the impact resistance of RAC (Dawson and Thom, 2011).

In this study, PVA fibers with different volume contents will be mixed into RAC modified by the nanosilica. The dynamic mechanical properties of the modified RAC will be tested through various RA replacement percentages and impact strain rates.

\section{EXPERIMENTAL PROCEDURE}

\section{Materials}

Ordinary Portland cement was used in this investigation. City tap water was used as the mixing water and additional water. The crushed rock was used as NA. RA was obtained and sieved by crushed waste concrete beams in the laboratory; the strength grade of the waste concrete was C40. The physical properties of the NA, RA, and the nanosilicarecycled aggregates (SRAs) are shown in Table 1. The fine aggregate was river sand with a fineness modulus of 2.7 and a bulk density of $1,460 \mathrm{~kg} / \mathrm{m}^{3}$. The properties and composition of the nanosilica solution are shown in Table 2. The physical properties of the PVA fiber are shown in Table 3. A superplasticizer was added to ensure the dispersion of nanoparticles and control the fluidity of RAC, for which the water reduction rate is $31 \%$.

TABLE 2 | Properties and composition of the nanosilica solution.

\begin{tabular}{|c|c|c|c|c|c|c|}
\hline Component & Exterior & Specific gravity/(g/ml) & $\mathrm{SiO}_{2}$ Solid content/\% & $\mathrm{Na}_{2} \mathrm{O} / \%$ & Viscosity/cp & $\mathrm{pH}$ value \\
\hline Nanosilica solution & Transparent glue & 1.205 & 30 & 0.28 & 5.0 & 9.7 \\
\hline
\end{tabular}


TABLE 3 | Physical properties of the polyvinyl alcohol (PVA) fiber.

\begin{tabular}{lcccc}
\hline Component & $\begin{array}{c}\text { Fiber } \\
\text { length/mm }\end{array}$ & $\begin{array}{c}\text { Fiber } \\
\text { diameter/ } \boldsymbol{\mu m}\end{array}$ & $\begin{array}{c}\text { Elongation } \\
\text { at break/\% }\end{array}$ & $\begin{array}{c}\text { Young's } \\
\text { modulus/MPa }\end{array}$ \\
\hline PVA fiber & 18 & 19 & 7 & $29 \times 10^{3}$ \\
\hline
\end{tabular}

\section{Concrete Specimen Preparation and Mixing Ratio}

The test variables were RA replacement percentage (mass fraction, 0,30 , and $100 \%$ ) and the content of PVA fiber (volume fraction, $0,0.05$, and $0.1 \%$ ). The RAs were pretreated by $2 \%$ (mass fraction) of modified nanosilica solution to make SRA. According to the China Standard for Sand and Stone Quality and Inspection Methods for Ordinary Concrete (JGJ52-2006) and the China Standard for Ordinary Concrete Mix Proportion Design (JGJ55-2011), the effective water-cement ratio and additional water consumption for RAC could be calculated. The mix proportions design of concrete is shown in Table 4. The superplasticizer, cement, fine aggregate, and mixing water of each group of concrete specimens were 1.85, 370, 779.69, and $170 \mathrm{~kg} / \mathrm{m}^{3}$, respectively.

The mechanical properties of RAC could be improved significantly by presoaking RAs in the nanosilica solution (Shaikh et al., 2018). The secondary stirring process could effectively improve the microstructure of the mixture, thereby enhancing the macro-mechanical properties of the RAC specimens (Tam et al., 2005). Therefore, this test followed this process: (1) Drying RA to a constant weight and adding it to the nanosilica solution soaking for $48 \mathrm{~h}$; (2)taking out the SRA until the saturated surface is dry and mixing with cement, sand, and NA for $1 \mathrm{~min}$; (3)adding half of the mixing water and superplasticizer and stirring for $1 \mathrm{~min}$; and (4) adding another half of the mixing water and PVA fiber and stirring for $2 \mathrm{~min}$, and then molding and curing.

\section{Test Design}

About $150 \mathrm{~mm} \times 150 \mathrm{~mm} \times 150 \mathrm{~mm}$-cubed RAC pieces were prepared according to the mixing ratio mentioned in Table 4 . The 28 days static compressive strength of each group of test pieces is shown in Table 5. $\Phi 50 \mathrm{~mm} \times 25 \mathrm{~mm}$ cylindrical test pieces could be made by cutting and polishing the cube RAC specimens and the flatness of cylindrical test pieces $\leq 0.02 \mathrm{~mm}$. The test used a $\Phi 50 \mathrm{~mm}$ separate variable cross-section split Hopkinson pressure bar (SHPB) device in the vibration laboratory of Henan Polytechnic University, as shown in Figure 1.

The SHPB air pressure was controlled to $0.20,0.25$, and $0.30 \mathrm{MPa}$, and the average strain rate was controlled to 20, 30, and $40 \mathrm{~s}^{-1}$. Petroleum jelly was applied to the section where the incident bar and the transmission bar contact the specimen to reduce frictional resistance, and then a pulse shaper (thin copper sheet) was pasted to control the constant strain rate in the test process. The incident wave $\varepsilon_{i}$, reflected wave $\varepsilon_{r}$, and transmitted wave $\varepsilon_{t}$ signals were collected through strain gauges. The two-wave method based on the one-dimensional elastic wave theory and the assumption of the stress was uniformly distributed along the bar (Huo et al., 2014), and the stress, strain, and strain rates were calculated to obtain the corresponding curves.

In this SHPB impact test, the typical strain-wave signal was collected using the dynamic strain gauge as shown in Figure 2; the microstrain $\mu \varepsilon$ is expressed in units of $10^{-6}$. The dynamic balance detection of the incident wave, the reflected wave, and the transmitted wave signals is depicted in Figure 3. Since this test only carried out two repeated impact tests on each group of the samples, the test results may have a

TABLE 4 | Mix proportions of concrete samples.

\begin{tabular}{|c|c|c|c|c|c|c|c|c|c|c|c|}
\hline \multirow[t]{2}{*}{ Number } & \multicolumn{5}{|c|}{ Material consumption $\left(\mathrm{kg} / \mathrm{m}^{3}\right)$} & \multirow[t]{2}{*}{ Number } & \multicolumn{5}{|c|}{ Materials consumption $\left(\mathrm{kg} / \mathrm{m}^{3}\right)$} \\
\hline & NA & RA & SRA & PVA fiber & Additional water & & NA & RA & SRA & PVA fiber & Additional water \\
\hline NPO & 1060.80 & 0 & 0 & 0 & 0 & R100P0.1 & 0 & 1060.80 & 0 & 1.30 & 40.73 \\
\hline NP0.05 & 1060.80 & 0 & 0 & 0.65 & 0 & SR30P0 & 742.56 & 0 & 318.24 & 0 & 11.64 \\
\hline NP0.1 & 1060.80 & 0 & 0 & 1.30 & 0 & SR30P0.05 & 742.56 & 0 & 318.24 & 0.65 & 11.64 \\
\hline R30P0 & 742.56 & 318.24 & 0 & 0 & 12.22 & SR30P0.1 & 742.56 & 0 & 318.24 & 1.30 & 11.64 \\
\hline R30P0.05 & 742.56 & 318.24 & 0 & 0.65 & 12.22 & SR100P0 & 0 & 0 & 1060.80 & 0 & 38.08 \\
\hline R30P0.1 & 742.56 & 318.24 & 0 & 1.30 & 12.22 & SR100P0.05 & 0 & 0 & 1060.80 & 0.65 & 38.08 \\
\hline R100P0 & 0 & 1060.80 & 0 & 0 & 40.73 & SR100P0.1 & 0 & 0 & 1060.80 & 1.30 & 38.08 \\
\hline R100P0.05 & 0 & 1060.80 & 0 & 0.65 & 40.73 & & & & & & \\
\hline
\end{tabular}

N, R, SR, and P represent NAC, RAC, SRAC, and PVA fiber, respectively. The numbers after the letters are variable values.

TABLE 5 | Compressive strength of concrete samples.

\begin{tabular}{|c|c|c|c|c|c|c|c|c|}
\hline Number & NPO & NP0.05 & NP0.1 & R30P0 & R30P0.05 & R30P0.1 & R100P0 & R100P0.05 \\
\hline Compressive strength (MPa) & 41.30 & 38.75 & 39.95 & 35.66 & 33.07 & 34.39 & 32.40 & 31.30 \\
\hline Number & R100P0.1 & SR30P0 & SR30P0.05 & SR30P0.1 & SR100P0 & SR100P0.05 & SR100P0.1 & \\
\hline Compressive strength (MPa) & 30.08 & 38.60 & 37.25 & 35.97 & 36.43 & 33.53 & 34.70 & \\
\hline
\end{tabular}




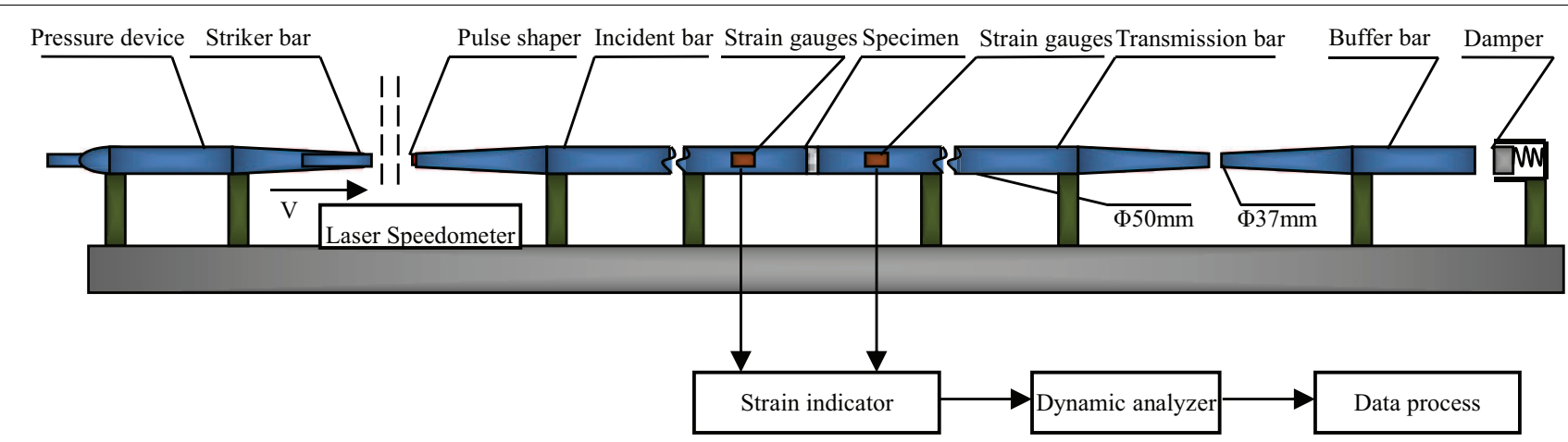

FIGURE 1 | Schematic of the 50 mm-diameter conic variable cross-section SHPB device. Abbreviation: SHPB, split Hopkinson pressure bar.

certain degree of dispersion. This study defines the average strain rate as the slope of the main straight line before the strain point corresponding to the peak stress in the straintime curve (Xiao et al., 2015). As shown in Figure 4, the slope of the red fitted line indicates that the representative strain rate is $21.67 \mathrm{~s}^{-1}$.

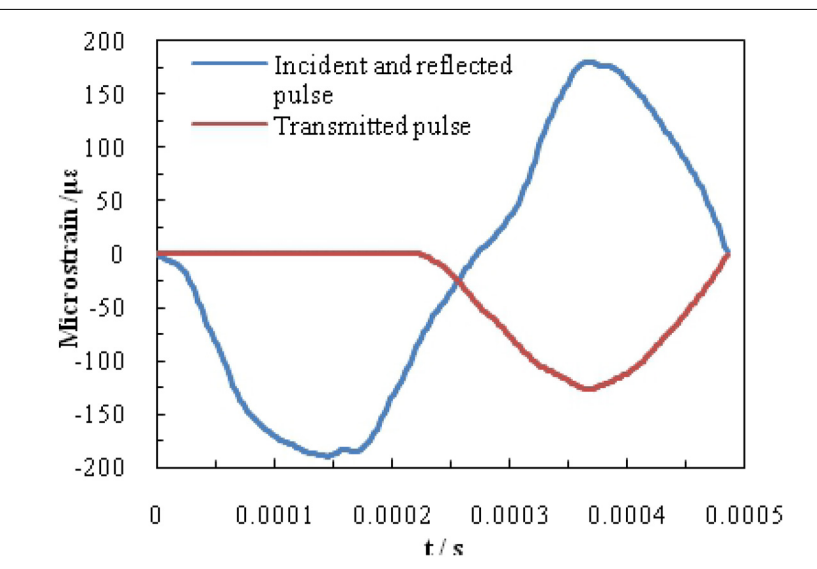

FIGURE 2 | Typical pulse signal history.

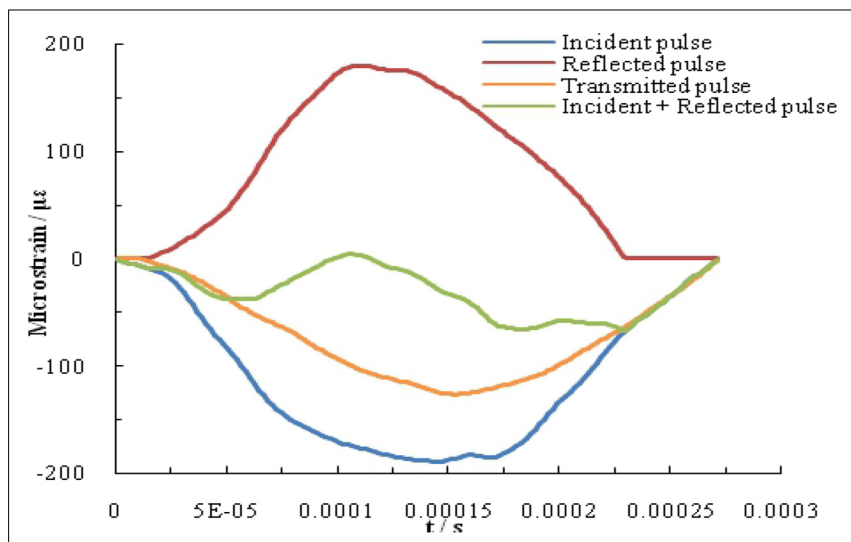

FIGURE 3 | Pulse signal dynamic balance test.

\section{TEST RESULTS AND ANALYSIS}

\section{Impact Failure Pattern}

The failure patterns of the specimens under different strain rates are shown in Figure 5. The failure patterns were characterized by the average value of the strain rate. The failure patterns of the RAC specimens in each group were roughly similar, and the specimens were most damaged at high strain rates. When the average strain rate was approximately $20 \mathrm{~s}^{-1}$, the specimen remains basically intact or has a few cracks, most of which were located near the edge of the impact center or at the edge of the specimen. When the average strain rate was approximately $30 \mathrm{~s}^{-1}$, the test piece was broken into large pieces with a small amount of the aggregate slag peeling off. When the average strain rate was approximately $40 \mathrm{~s}^{-1}$, the specimen was basically broken, and the broken shape was roughly a vertical strip. Most of the fracture surfaces of the specimens located at the ITZ between the mortar and the RA. Under the same strain rate, the increase of the RA replacement percentage aggravated the damage of the specimens; the PVA fiber penetrated the ITZ of $\mathrm{RAC}$ and inhibited the destruction of RAC by the bridging effect. As shown in Figure 5D, the smaller fragments adhered to the

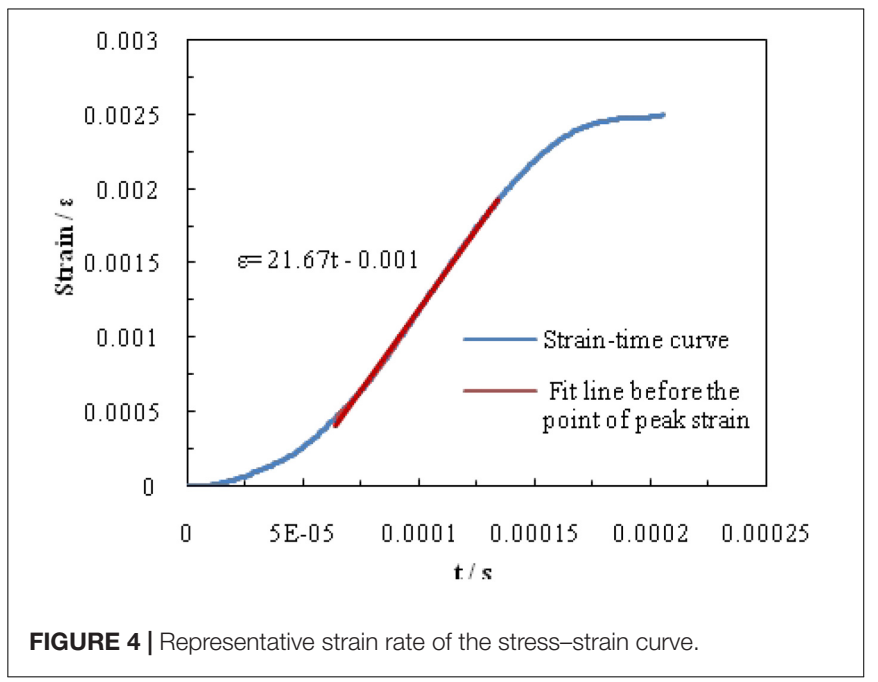




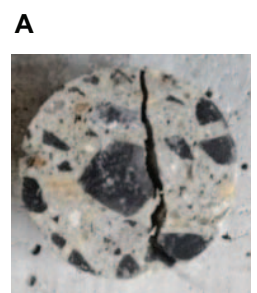

$20.40 \mathrm{~s}^{-1}$

C

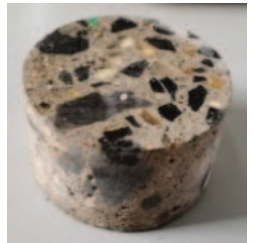

$18.60 \mathrm{~s}^{-1}$

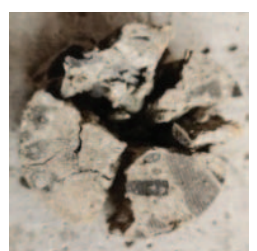

$32.20 \mathrm{~s}^{-1}$

SR30P0

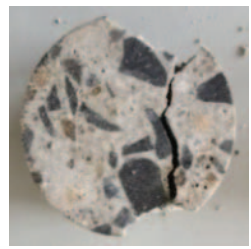

$29.71 \mathrm{~s}^{-1}$

SR100P0.05
B

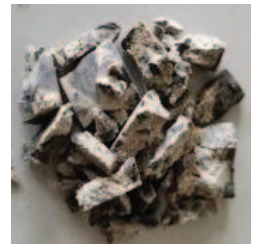

$41.90 \mathrm{~s}^{-1}$

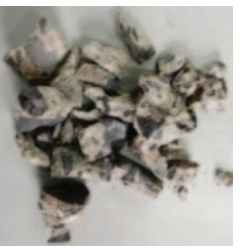

$43.58 \mathrm{~s}^{-1}$

(3)

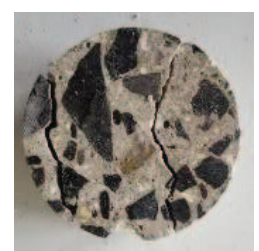

$22.70 \mathrm{~s}^{-1}$

D

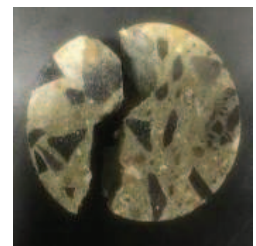

$22.50 \mathrm{~s}^{-1}$

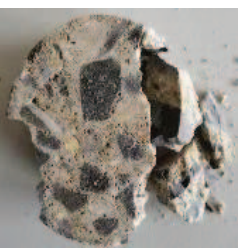

$31.90 \mathrm{~s}^{-1}$

SR100P0

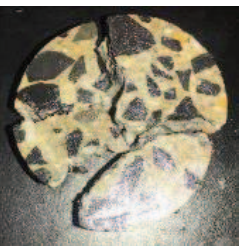

$31.04 \mathrm{~s}^{-1}$

SR100P0.1

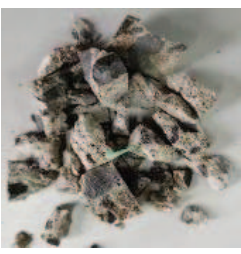

$43.60 \mathrm{~s}^{-1}$

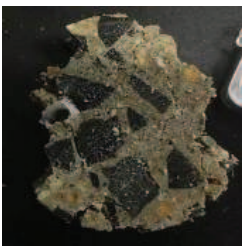

$44.52 \mathrm{~s}^{-1}$

FIGURE 5 | Failure patterns of the concrete specimens under different strain rates. (A) SR30P0, (B) SR100P0, (C) SR100P0.05, and (D) SR100P0.1.

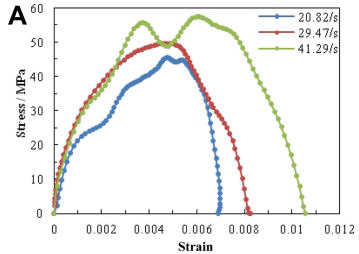

C

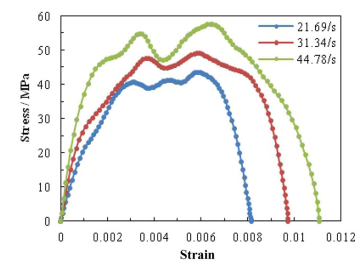

E

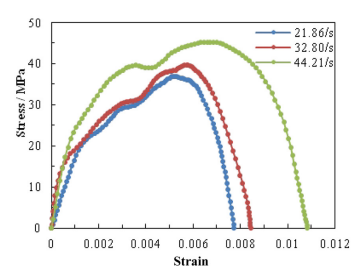

G

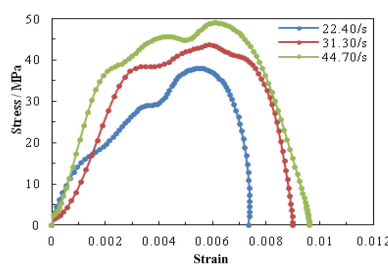

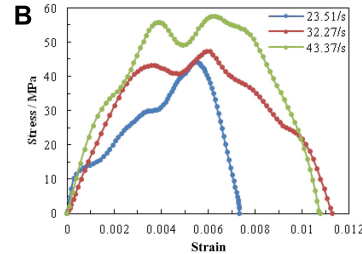

D

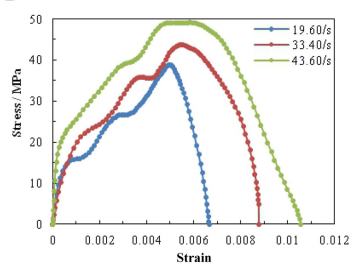

F

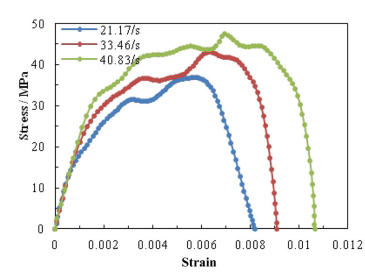

H

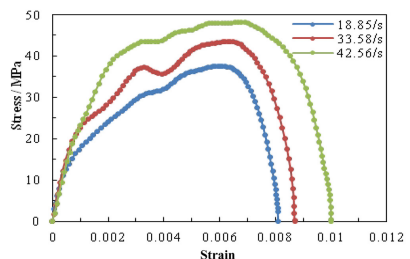

K
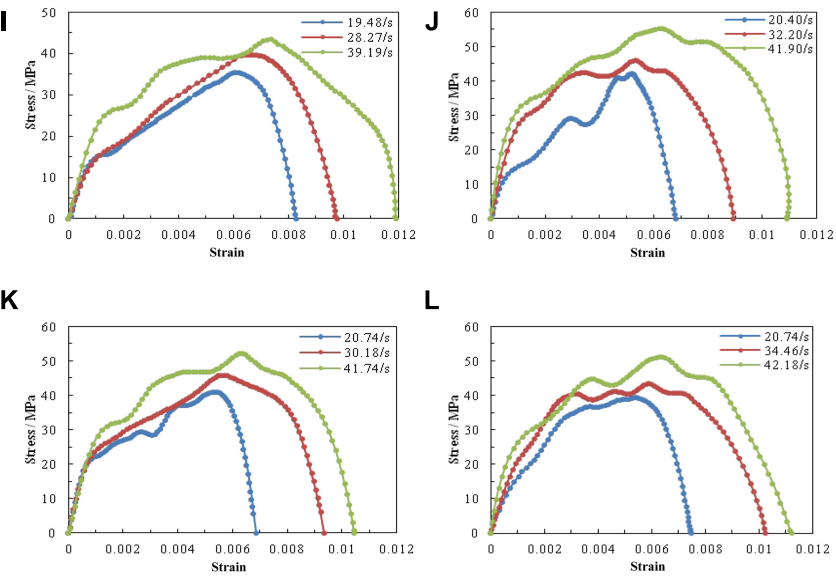

$\mathbf{L}$

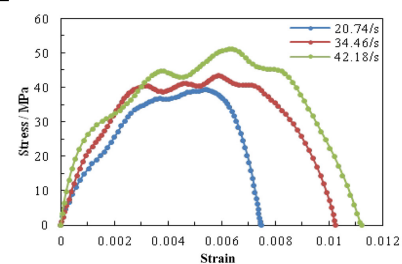

N
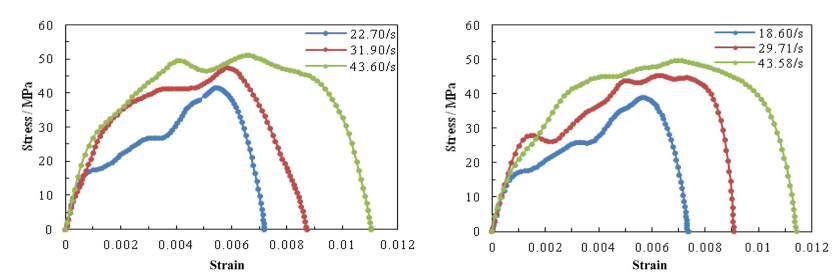

0

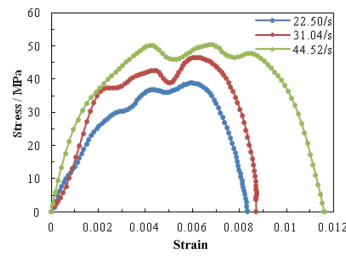

FIGURE 6 | Stress-strain curves of specimens under different strain rates. (A) NP0, (B) NP0.05, (C) NP0.1, (D) R30P0, (E) R30P0.05, (F) R30P0.1, (G) R100P0, (H) R100P0.05, (I) R100P0.1, (J) SR30P0, (K) SR30P0.05, (L) SR30P0.1, (M) SR100P0, (N) SR100P0.05, and (O) SR100P0.1. 
larger, and some PVA fibers could be seen at the fracture surface of the specimen.

\section{Dynamic Stress-Strain Curve}

Under different parameter change conditions, the stress-strain curves of each group of specimens show the same change trend, as shown in Figure 6. As the strain rate increases, the peak stress and the initial elastic modulus of the specimens increase. This may be the result of the combination of viscous effects, crack propagation effects, and inertial effects (Xiao et al., 2015). For NAC specimens, the stress-strain curve shows two adjacent peaks, due to the non-uniform distribution of the coarse aggregate, as shown in Figures 6A-C). However, it may also be related to the larger particle size of the coarse aggregate selected during the preparation of the specimen. Compared to NAC, the curves of the peak stress area of RAC and its modified specimens change more smoothly, and the change values do not appear to be greatly shifted, indicating that the incorporation of the nanosilica and RA has the potential to improve the ductility of RAC.

The area enveloped under the stress-strain curve of the specimen is shown as the specific energy absorption, which can reflect the impact toughness of the specimen ( $\mathrm{Lu}$ et al., 2014). Under a high strain rate, the envelope area of the stressstrain curve of the specimen increases, showing higher impact toughness, as shown in Figure 6. Moreover, as the strain rate increases, the stress and strain value of the specimen also increases. Incorporating the PVA fiber and RA modification can improve the strength of the specimen. Under the condition of a higher strain rate, the improvement of the strength of the modified specimen will be weakened.

\section{Test Parameter}

In order to show the effect of design parameters on the stress and strain value of the specimen more detailed, the stress-strain curves of the specimens with the strain rate of approximately $20 \mathrm{~s}^{-1}$ are selected as a reference, as shown in Figure 7. As the RA replacement percentage increases, the stress value of the specimen follows a downward trend, while the strain value shows an increasing trend, as shown in Figure 7A. With the increase of the PVA fiber content, the strain value of the specimen shows a different trend, while the dynamic peak strain shows an increasing trend, as shown in Figure $\mathbf{7 B}$. When the fiber content is $0.05 \%$, the strain value of the nanosilica-modified specimen is less affected; when the fiber content is $0.1 \%$, the ultimate strain value of the specimen increases significantly. Dynamic peak stress of RAC is significantly increased by the SRA, as shown in Figure 7C. It may be the hydrated calcium silicate gel produced by the pozzolanic reaction between
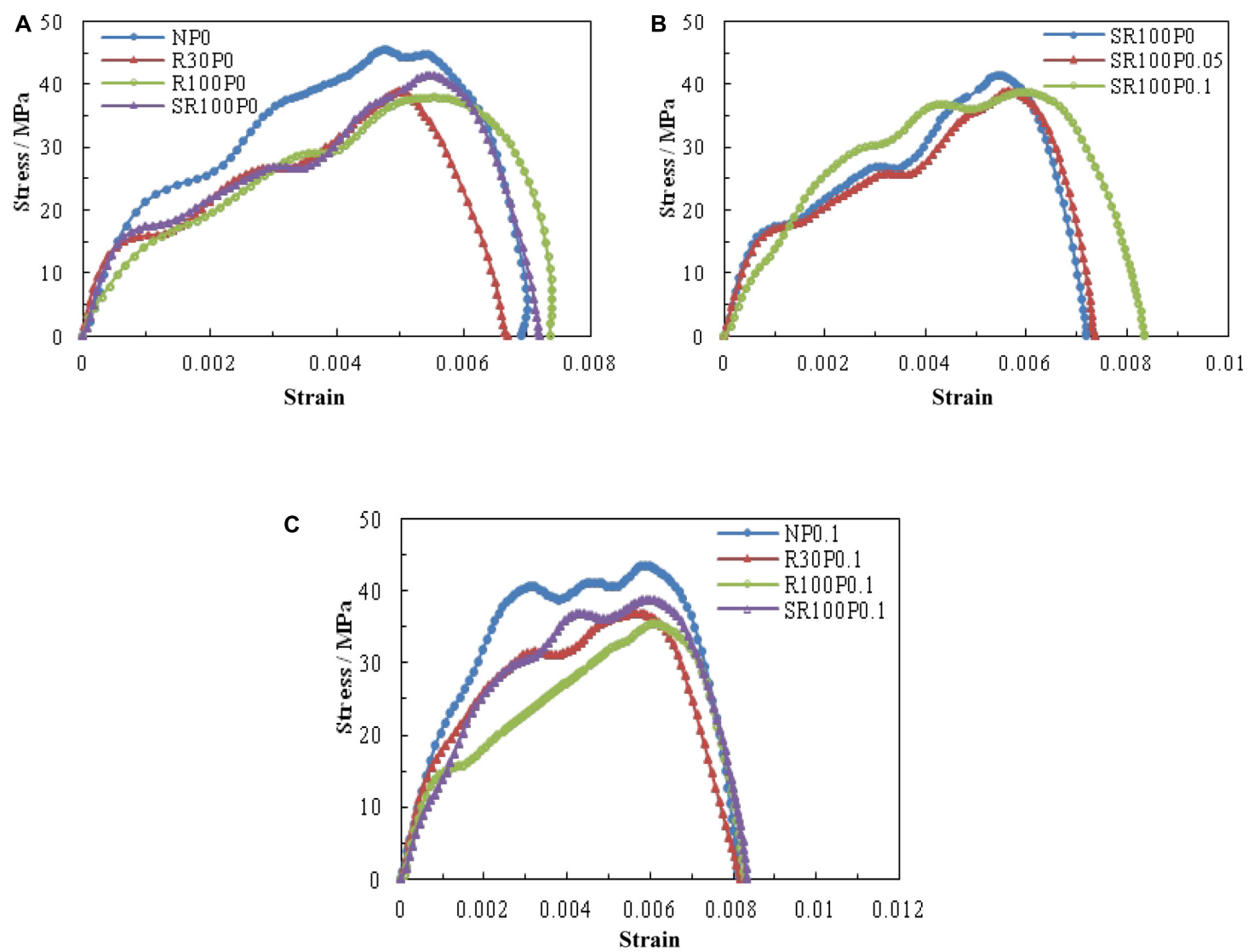

FIGURE 7 | Comparison of stress-strain curves of the specimens under the strain rate of approximately $20 \mathrm{~s}^{-1}$. (A) Effect of the RA replacement percentage. (B) Effect of the PVA fiber content. (C) Effect of nanosilica-modified recycled aggregate. 
nanosilica and $\mathrm{Ca}(\mathrm{OH})_{2}$ that strengthens the ITZ and improves the strength of the RAC specimen (Hosseini et al., 2011; Wang et al., 2020).

\section{Dynamic Impact Strength}

The dynamic impact strength of the specimen under variable conditions is shown in Figures 8, 9. NAC exhibits a higher

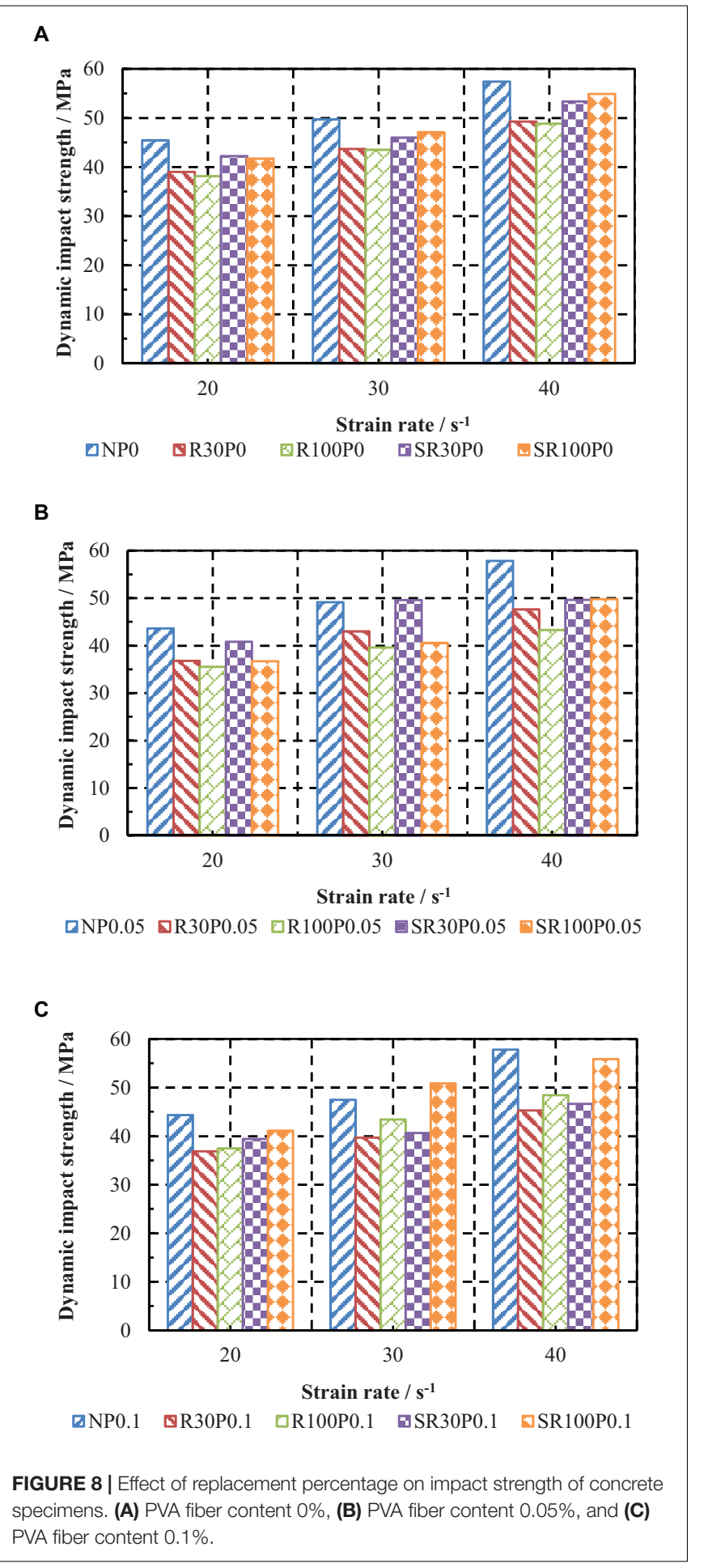

dynamic impact strength. As the RA replacement percentage increases, the dynamic impact strength of the specimens shows a downward trend. With the increase of the strain rate, the dynamic impact strength of the specimen shows an increasing

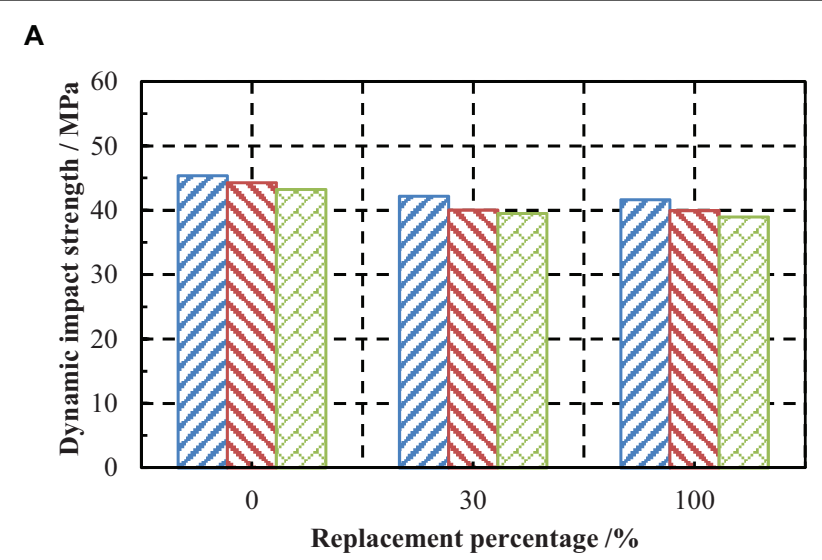

$\square$ Fiber content $0 \% \quad$ aFiber content $0.05 \% \quad \square$ Fiber content $0.1 \%$

B

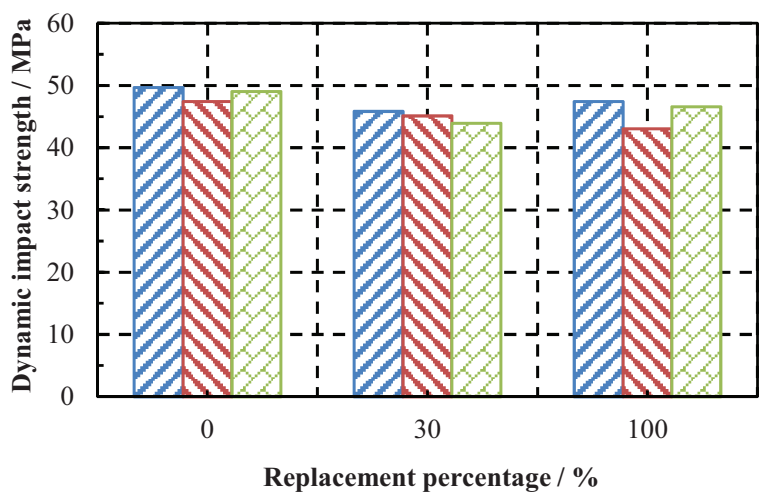

$\square$ Fiber content $0 \% \quad$ aFiber content $0.05 \% \quad \square$ Fiber content $0.1 \%$

C

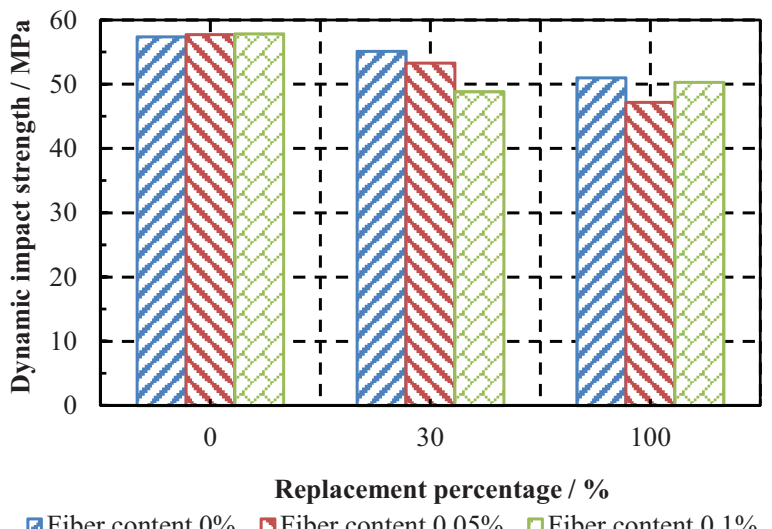

FIGURE 9 | Effect of PVA fiber content on impact strength of concrete specimens. (A) Average strain rate $20 \mathrm{~s}^{-1}$, (B) Average strain rate $30 \mathrm{~s}^{-1}$, and (C) Average strain rate $40 \mathrm{~s}^{-1}$. 

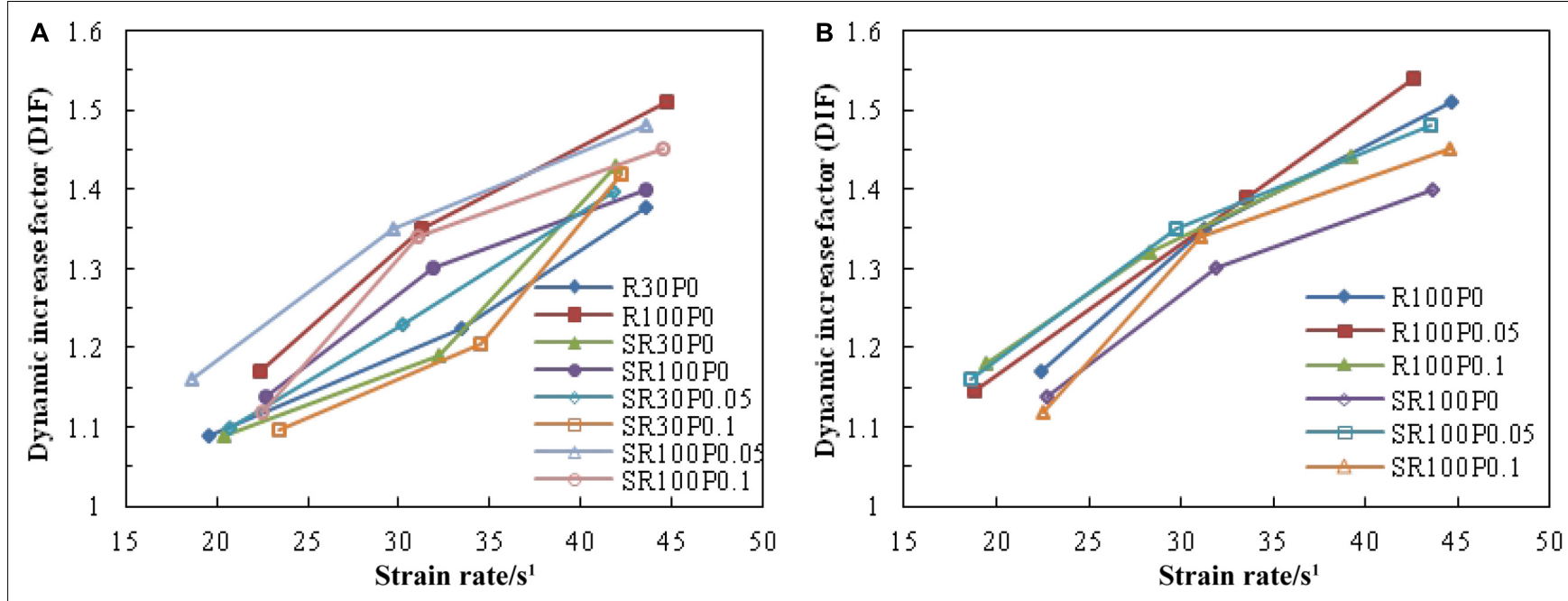

FIGURE 10 | Dynamic increase factor (DIF) of impact specimens. (A) Different RA replacement percentage. (B) RA replacement percentage100\%.

trend, which may be caused by the strain rate effect ( $\mathrm{Lu}$ et al., 2014; Wang et al., 2020). Under the same conditions of the RA replacement percentage ( 30 and $100 \%$ ) and the PVA fiber content $(0,0.05$, and $0.1 \%)$, when the average strain rate is approximately $20 \mathrm{~s}^{-1}$, the dynamic impact strength of nanosilica-modified RAC is higher than that of RAC by 8.23 and $9.36 \%, 10.88$ and $3.33 \%$, and 6.92 and $9.63 \%$, respectively; when the average strain rate is approximately $30 \mathrm{~s}^{-1}$, the dynamic impact strength of nanosilicamodified RAC is higher than that of RAC by 5.2 and $8.28 \%, 15.42$ and $2.46 \%$, and 2.47 and $17.13 \%$, respectively; when the average strain rate is approximately $40 \mathrm{~s}^{-1}$, the dynamic impact strength of nanosilica-modified RAC is increased by 8.24 and $12.38 \%, 4.25$ and $15.02 \%$, and 2.95 and $15.36 \%$ compared to RAC, respectively. The reason may be that nanosilica improves the performance of the ITZ through the pozzolanic reaction and the filling of the pores of the C-S-H gel structure (Mukharjee and Barai, 2014).

With the increase of the PVA fiber content, the dynamic impact strength of the specimens shows a different downward trend, as shown in Figure 9. Under the same conditions of strain rate $\left(20,30\right.$, or $\left.40 \mathrm{~s}^{-1}\right)$, when RA replacement percentage is $30 \%$, with the increase of PVA fiber content, the dynamic impact strength of nanosilica-modified RAC decreases by 5.17 and $6.32 \%, 1.53$ and $4.1 \%$, and 3.32 and $11.37 \%$, respectively; when the replacement percentage is $100 \%$, the dynamic impact strength of the specimen is reduced by 3.98 and $6.39 \%, 9.24$ and $1.82 \%$, and 7.5 and $1.35 \%$, respectively. The reason may be due to air-entraining effect of the PVA fiber incorporation, which increases the gas content of the RAC, or it may be affected by the water-binder ratio, resulting in a decrease in the bonding performance between the PVA fiber and RAC.

\section{Dynamic Increase Factor}

The ratio of the dynamic peak stress of the specimen to the static compressive strength is defined as the DIF of the specimen. The DIF of the specimen is shown in Figure 10. Under the conditions of various strain rates, with the increase of RA replacement percentage, the DIF value shows an upward trend, as shown in Figure 10A. When RA replacement percentage is $100 \%$, the DIF value of RAC has the maximum increase. This may be due to more damaged areas in RAC and most of the cracks appearing in the ITZ, under the same load (Poon et al., 2004; Tam et al., 2005). When the RA replacement percentage is $100 \%$, the DIF value of RAC is greater than that of the nanosilica-modified RAC, as shown in Figure 10B. This shows that RAC has a higher strain rate sensitivity (Xiao et al., 2015), while the strain rate sensitivity of nanosilica RAC is lower (Wang et al., 2020), and nanosilica modification has a good improvement potential for impact performance. With the increase of the PVA fiber content, the DIF value of RAC specimens shows an increasing trend. The DIF value of nanosilica-modified RAC increases with an increase in the PVA fiber content.

As the strain rate increases, the DIF of each group of specimens shows an increasing trend, as shown in Figure 10. When the strain rate is approximately $30 \mathrm{~s}^{-1}$, the DIF curve has a special zone, which may be the beginning point of the specimen to reach the elastoplastic statement. The incorporation of nanosilica and PVA fiber makes the curve smoother, which can improve the change of DIF values to a certain extent as shown in Figure 10B.

\section{CONCLUSION}

The impact performance of the nanosilica-modified RAC mixed with PVA fibers was tested under various strain rates ranging from 20 to $40 \mathrm{~s}^{-1}$.

(1) As the RA replacement percentage increases, the dynamic impact strength of RAC and nanosilica-modified RAC decreases, while the strain and the DIF values of the specimen increase. When the RA replacement percentage is $100 \%$, the impact performance of the specimens decreases most significantly. 
(2) Nanosilica modification can improve the dynamic impact strength of RAC. With the increase of the RA replacement percentage and the strain rate, the effect of nanosilica modification will be weakened.

(3) The bridging effect of the PVA fiber mixing in RAC improves the strain value of the specimen and changes the failure pattern. When the amount of PVA fiber is $0.1 \%$, the deformation ability of the specimen is improved mostly.

(4) With the increase of the strain rate, the stress and strain values of the test specimens increase, and the strain rate sensitivity of RAC becomes higher. However, nanosilicamodified RAC shows lower strain rate sensitivity.

\section{DATA AVAILABILITY STATEMENT}

The original contributions presented in the study are included in the article/supplementary material,

\section{REFERENCES}

Bernal, J., Reyes, E., Massana, J., León, N., and Sánchez, E. (2018). Fresh and mechanical behavior of a self-compacting concrete with additions of nanosilica, silica fume and ternary mixtures. Constr. Build. Mater. 160, 196-210. doi: 10.1016/j.conbuildmat.2017.11.048

Dawson, A. R., and Thom, N. H. (2011). Microstructure-linked strength properties and impact response of conventional and recycled concrete reinforced with steel and synthetic macro fibres. Constr. Build. Mater. 25, 4025-4036. doi: 10.1016/j. conbuildmat.2011.04.037

Hansen, T. C. (1986). Recycled aggregates and recycled aggregate concrete second state-of-the-art report developments 1945-1985. Mater. Struct. 19, 201-246. doi: 10.1007/BF02472036

Hosseini, P., Booshehrian, A., and Madari, A. (2011). Developing concrete recycling strategies by utilization of nano-SiO 2 particles. Waste Biomass Valorization. 2, 347-355. doi: 10.1007/s12649-011-9071-9

Huo, J., He, Y., and Chen, B. (2014). Experimental study on impact behaviour of concrete-filled steel tubes at elevated temperatures up to 800 C. Mater. Struct. Constr. 47, 263-283. doi: 10.1617/s11527-013-0059-8

Jalal, A., Shafiq, N., Nikbakht, E., Kumar, R., and Zahid, M. (2017). Mechanical properties of hybrid basalt-polyvinyl alcohol (PVA) fiber reinforced concrete. Key Eng. Mater. 744, 3-7. doi: 10.4028/www.scientific.net/kem. 744.3

Kou, S. C., and Poon, C. S. (2010). Properties of concrete prepared with PVAimpregnated recycled concrete aggregates. Cem. Concr. Compos. 32, 649-654. doi: 10.1016/j.cemconcomp.2010.05.003

Li, W., Huang, Z., Cao, F., Sun, Z., and Shah, S. P. (2015). Effects of nano-silica and nano-limestone on flowability and mechanical properties of ultra-highperformance concrete matrix. Constr. Build. Mater. 95, 366-374. doi: 10.1016/j. conbuildmat.2015.05.137

Li, W., Luo, Z., Long, C., Wu, C., Duan, W. H., and Shah, S. P. (2016). Effects of nanoparticle on the dynamic behaviors of recycled aggregate concrete under impact loading. Mater. Des. 112, 58-66. doi: 10.1016/j.matdes.2016.09.045

Liu, F., Feng, W., Xiong, Z., Tu, G., and Li, L. (2018). Static and impact behaviour of recycled aggregate concrete under daily temperature variations. J. Clean. Prod. 191, 283-296. doi: 10.1016/j.jclepro.2018.04.237

Lu, Y., Chen, X., Teng, X., and Zhang, S. (2014). Dynamic compressive behavior of recycled aggregate concrete based on split Hopkinson pressure bar tests. Lat. Am. J. Solids Struct. 11, 131-141. doi: 10.1590/S1679-7825201400010 0008

Manzi, S., Mazzotti, C., and Bignozzi, M. C. (2013). Short and long-term behavior of structural concrete with recycled concrete aggregate. Cem. Concr. Compos. 37, 312-318. doi: 10.1016/j.cemconcomp.2013.01.003 further inquiries can be directed to the corresponding author/s.

\section{AUTHOR CONTRIBUTIONS}

$\mathrm{XW}$ : conceptualization, methodology, and writing-original draft. MJ: writing-software. XZ and ZC: writing-review and editing. JG and FC: test and software. All authors contributed to the article and approved the submitted version.

\section{FUNDING}

The authors are grateful for the Fundamental Research Funds for the Universities of Henan Province (Henan Polytechnic University, NSFRF200328 and NSFRF200320) and the Henan Key Laboratory of Special Protective Materials (Grant No. SZKFJJ202004).

Mohanraj, E. K., Kandasamy, S., and Malathy, R. (2011). Behavior of steel tubular stub and slender columns filled with concrete using recycled aggregates. J. South Afr. Inst. Civ. Eng. 53, 31-38.

Mukharjee, B. B., and Barai, S. V. (2014). Influence of Nano-Silica on the properties of recycled aggregate concrete. Constr. Build. Mater. 55, 29-37. doi: 10.1016/j. conbuildmat.2014.01.003

Poon, C. S., Shui, Z. H., and Lam, L. (2004). Effect of microstructure of ITZ on compressive strength of concrete prepared with recycled aggregates. Constr. Build. Mater. 18, 461-468. doi: 10.1016/j.conbuildmat.2004. 03.005

Richardson, I. G. (1999). Nature of C-S-H in hardened cements. Cem. Concr. Res. 29, 1131-1147. doi: 10.1016/S0008-8846(99)00168-4

Shaikh, F., Chavda, V., Minhaj, N., and Arel, H. S. (2018). Effect of mixing methods of nano silica on properties of recycled aggregate concrete. Struct. Concr. 19, 387-399. doi: 10.1002/suco.201700091

Tabsh, S. W., and Abdelfatah, A. S. (2009). Influence of recycled concrete aggregates on strength properties of concrete. Constr. Build. Mater. 23, 1163-1167. doi: 10.1016/j.conbuildmat.2008.06.007

Tam, V. W. Y., Gao, X. F., and Tam, C. M. (2005). Microstructural analysis of recycled aggregate concrete produced from two-stage mixing approach. Cem. Concr. Res. 35, 1195-1203. doi: 10.1016/j.cemconres.2004.10.025

Tangchirapat, W., Buranasing, R., and Jaturapitakkul, C. (2010). Use of high fineness of fly ash to improve properties of recycled aggregate concrete. J. Mater. Civ. Eng. 22, 565-571. doi: 10.1061/(asce)mt.1943-5533.0000054

Their, J. M., and Özakça, M. (2018). Developing geopolymer concrete by using cold-bonded fly ash aggregate, nano-silica, and steel fiber. Constr. Build. Mater. 180, 12-22. doi: 10.1016/j.conbuildmat.2018.05.274

Thomas, J., Thaickavil, N. N., and Wilson, P. M. (2018). Strength and durability of concrete containing recycled concrete aggregates. J. Build. Eng. 19, 349-365. doi: 10.1016/j.jobe.2018.05.007

Topçu, I. B., and Şengel, S. (2004). Properties of concretes produced with waste concrete aggregate. Cem. Concr. Res. 34, 1307-1312. doi: 10.1016/j.cemconres. 2003.12.019

Wang, L., Zhou, S. H., Shi, Y., Tang, S. W., and Chen, E. (2017). Effect of silica fume and PVA fiber on the abrasion resistance and volume stability of concrete. Compos. Part B Eng. 130, 28-37. doi: 10.1016/j.compositesb.2017.07.058

Wang, X., Cheng, F., Wang, Y., Zhang, X., and Niu, H. (2020). Impact properties of recycled aggregate concrete with nanosilica modification. Adv. Civ. Eng. 2020:8878368. doi: 10.1155/2020/8878368

Wang, Y., Li, S., Hughes, P., and Fan, Y. (2020). Mechanical properties and microstructure of basalt fibre and nano-silica reinforced recycled concrete after exposure to elevated temperatures. Constr. Build. Mater. 247:118561. doi: 10. 1016/j.conbuildmat.2020.118561 
Xiao, J., Li, L., Shen, L., and Poon, C. S. (2015). Compressive behaviour of recycled aggregate concrete under impact loading. Cem. Concr. Res. 71, 46-55. doi: 10.1016/j.cemconres.2015.01.014

Xiao, J., Li, W., Fan, Y., and Huang, X. (2012). An overview of study on recycled aggregate concrete in China (1996-2011). Constr. Build. Mater. 31, 364-383. doi: 10.1016/j.conbuildmat.2011.12.074

Yaowarat, T., Horpibulsuk, S., Arulrajah, A., Mirzababaei, M., Safuan, A., and Rashid, A. S. A. (2018). Compressive and flexural strength of polyvinyl alcohol-modified pavement concrete using recycled concrete aggregates. J. Mater. Civ. Eng. 30:04018046. doi: 10.1061/(asce)mt.1943-5533.000 2233

Zhang, H., Zhao, Y., Meng, T., and Shah, S. P. (2015). The modification effects of a nano-silica slurry on microstructure, strength, and strain development of recycled aggregate concrete applied in an enlarged structural test. Constr. Build. Mater. 95, 721-735. doi: 10.1016/j.conbuildmat.2015.07. 089

Conflict of Interest: The authors declare that the research was conducted in the absence of any commercial or financial relationships that could be construed as a potential conflict of interest.

Copyright (๑ 2021 Wang, Jiang, Zhang, Cheng, Gong and Cheng. This is an openaccess article distributed under the terms of the Creative Commons Attribution License (CC BY). The use, distribution or reproduction in other forums is permitted, provided the original author(s) and the copyright owner(s) are credited and that the original publication in this journal is cited, in accordance with accepted academic practice. No use, distribution or reproduction is permitted which does not comply with these terms. 